Article

\title{
Experiences of Diabetes Self-Management: A Focus Group Study among the Middle-Aged Population of Rural Pakistan with Type 2 Diabetes
}

\author{
Rashid M. Ansari ${ }^{1, * \mathbb{D}}$, Mark F. Harris ${ }^{2}$, Hassan Hosseinzadeh ${ }^{3} \mathbb{D}$ and Nicholas Zwar 4 \\ 1 School of Population Health, Faculty of Medicine, University of New South Wale, \\ Sydney, NSW 2052, Australia \\ 2 Centre for Primary Health Care and Equity, University of New South Wale, Sydney, NSW 2052, Australia; \\ m.f.harris@unsw.edu.au \\ 3 School of Health and Society, Faculty of Medicine and Health, University of Wollongong (UOW), \\ Sydney, NSW 2522, Australia; hassanh@uow.edu.au \\ 4 Faculty of Health Sciences and Medicine, Bond University, Gold Coast, QLD 4226, Australia; \\ nzwar@bond.edu.au \\ * Correspondence: rashid.ansari@uqconnect.edu.au
}

check for updates

Citation: Ansari, R.M.; Harris, M.F.; Hosseinzadeh, H.; Zwar, N. Experiences of Diabetes Self-Management: A Focus Group Study among the Middle-Aged Population of Rural Pakistan with Type 2 Diabetes. Diabetology 2022, 3, 17-29. https://doi.org/10.3390/ diabetology3010002

Academic Editor: Peter Clifton

Received: 4 December 2021

Accepted: 5 January 2022

Published: 6 January 2022

Publisher's Note: MDPI stays neutral with regard to jurisdictional claims in published maps and institutional affiliations.

Copyright: (c) 2022 by the authors. Licensee MDPI, Basel, Switzerland. This article is an open access article distributed under the terms and conditions of the Creative Commons Attribution (CC BY) license (https:// creativecommons.org/licenses/by/ $4.0 /)$.

\begin{abstract}
Objectives: The middle-aged population from rural areas of Pakistan is disproportionately at risk of developing and mismanaging their diabetes. The purpose of this study was to explore the self-management experiences of two focus groups in the middle-aged population with type 2 diabetes mellitus living in rural Pakistan. Methods: The study design is based on the exploratory research using a qualitative approach. Purposive sampling was used to recruit patients with diabetes from the metabolic outpatient clinics of medical centers in rural areas of Pakistan. The data were collected for two focus groups consisting of 20 persons (10 men and 10 women) with type 2 diabetes mellitus, ranging in age from 40 to 65 years, who were receiving diabetic care at a local health facility. Focus group discussions with a sample size of 10 participants each were all recorded, transcribed, and analyzed. The data were evaluated thematically. Results: Participants described diabetes management as emotionally, physically, and socially taxing. The analysis of the data indicated three major themes: (1) diabetes as a challenging disease; (2) understanding diabetes and its challenges; (3) following diabetes self-management practices. Throughout the session, participants discussed the impact of diabetes on their daily life. This study provided new insights into the experiences of the middle-aged population of Pakistan regarding their self-management of diabetes. Conclusions: Healthcare professionals should become involved in diabetes self-management education as soon as feasible to alleviate patient worry and establish better patient-centered, culturally sensitive professional abilities. Along with monitoring patients' self-management, healthcare professionals should place a greater emphasis on patients' understanding of the disease and its challenges and associated complications. It is recommended to establish diabetes support groups to encourage patients to share their experiences of diabetes self-management.
\end{abstract}

Keywords: focus groups; self-management of type 2 diabetes; patients' experiences; healthcare professionals; middle-aged population

\section{Introduction}

Diabetes mellitus is one of the most prevalent chronic diseases worldwide, creating a slew of health problems for the population [1]. According to the International Diabetes Federation (IDF), there are 463 million individuals worldwide who have diabetes [2], with type 2 diabetes being more prevalent in people aged 40 to 59 years [2,3].

The prevalence of type 2 diabetes in Pakistan is in the range of 7.6\% (5.2 million populations) to $11 \%$ [3-5], and it is estimated that it will increase to around $15 \%$ (14 million 
populations) by 2030. Pakistan ranks in the top 10 countries worldwide in terms of diabetes prevalence among people aged 20 to 79 years [2].

This population is at increased risk of type 2 diabetes due to a higher prevalence of overweight or obesity, physical inactivity, and unhealthy eating habits associated with a sedentary lifestyle [1,2]. Additionally, the Pakistani region has a population with numerous social and health inequities, which contribute to the region's high prevalence of diabetes and obesity [3-6].

Self-management is defined as a patient's active participation in his or her own treatment and well-being [7]. Self-management has been described by Corbin and Strauss [8] as having three main activities: (1) adherence to medication, which includes following the dietary recommendations; (2) behavioral management, which includes new lifestyle modification; and (3) emotional management, which includes coping with chronic diseaserelated feelings of frustration, fear, and despair. Because type 2 diabetes is a chronic disease involving just a few visits per year to health care providers, individuals must manage all of these components on their own for the rest of their lives.

The optimized self-management addresses all three main activities of the Corbin and Strauss framework [8] and encourages physicians and patients to work collaboratively to "identify problems, determine priorities, develop goals, build treatment plans, and resolve conflicts along the way" [9]. Previous research has demonstrated that successfully assisting patients with type 2 diabetes in self-management resulted in beneficial effect on their lifestyle and, eventually, helped in improving the health outcomes [10-12]. However, worldwide research indicates that the self-management support is still insufficient in many parts of the world [13].

Therefore, a thorough understanding of public health perspectives on self-management and how it is currently supported could aid in the creation of solutions that are more tailored to the requirements of patients, preferences, and skills. Appropriate self-management support is likely to improve health outcomes and care efficiency [13].

Self-management of diabetes is a critical activity for diabetes patients in their daily lives and is regarded as the cornerstone of diabetes care in the literature [14]. Numerous studies in the literature have emphasized the relevance of diabetes self-management and its association with increased diabetes awareness, responsible patient behavior toward their disease, and clinical success [15-17].

Diabetes mellitus has a negative impact on numerous facets on the daily life of a person. Therefore, structured individual care is generally connected with a better control of blood sugar [18]. Diabetic self-management education is the process by which individuals acquire the required knowledge and abilities for diabetes self-care [19]. Diabetes care on a daily basis (healthy diet, physical activity, blood sugar testing, and adherence to medication) is primarily the patient's responsibility; hence, people must be educated to carry out self-management activities properly. Substantial research work has been carried out to determine the numerous elements that influence self-management in people with diabetes $[14,18,19]$.

The main objective of this research work was to explore the understanding and experiences of the focus groups about the self-management activities of Pakistan's middle-aged population with type 2 diabetes. Focus group discussion is frequently used as a qualitative approach to gain an in-depth understanding of social issues. Focus groups are about insight through guided group discussion, where participants share their thoughts, feelings, attitudes, and ideas on subjects. Exploring such rich experiences and gaining a better understanding of diabetes self-management activities promotes the development of more effective techniques for teaching diabetes self-management so that afflicted individuals may manage the condition effectively and coexist with it. 


\section{Methods}

\subsection{Study Design}

The purpose of this qualitative study was to collect information regarding the selfmanagement experiences of a middle-aged population with type 2 diabetes mellitus residing in rural Pakistan through focus group interviews [20]. For this study, two focus group interviews were conducted away from the medical clinics, in the main auditorium of Al-Rehman hospital in Abbottabad, Pakistan. The study design is based on the exploratory research using a qualitative approach. The purposive sampling was used to recruit patients with diabetes from the outpatient clinics of medical centers in rural areas of Pakistan.

\subsection{Setting and Sample Size}

Patients with diabetes were recruited through purposive sampling from metabolic outpatient clinics in rural medical centers in Abbottabad, Pakistan. The estimated population of Abbottabad city in 2010 was 1.1719 million [3,5]. The city is located in the north of Pakistan about $110 \mathrm{~km}$ from Islamabad (the capital city). Around $80 \%$ of the population lives in rural areas, there are 19 primary healthcare clinics in that area, and five of these clinics are associated with the hospital where this study was conducted [3,5].

The following criteria were used to determine inclusion: (a) a minimum age of 40 years, (b) a diagnosis of type 2 diabetes five years' prior, (c) a willingness to openly communicate their experiences and engage in conversation, and (d) willingness to be audio-recorded. The patients with coexisting liver, kidney, or thyroid disorder and under treatment at the time of the study were excluded. Patients with cognitive impairment, major psychiatric diagnosis, or surgery were also excluded.

A purposive sample of 20 participants was selected in this study. The purposive sampling is a suitable sampling method in qualitative studies to identify and select informationrich respondents to a phenomenon of interest, which was the self-management of diabetes mellitus in this study [20,21]. Therefore, this sampling approach was used to determine the sample size based on theoretical saturation, a point during data collection when new data does not bring additional insights into the research question or themes.

This small sample size is adequate enough to allow in depth exploration of the experiences of patients regarding the self-management of type 2 diabetes [20-22]. Carolan et al. [23] used a sample size of 22 participants to conduct the qualitative study for the focus groups. The aim of this study was to explore the experiences and concerns of individuals with type 2 diabetes mellitus, in a predominantly low socio-economic setting. Wu et al. [24] conducted a qualitative study with two focus groups, comprising a total of 23 participants, to collect data, and group discussions were held a total of four times in an education room. Mathew et al. [25] recruited 35 participants from a diabetes education center (DEC) in Toronto, Canada to conduct the qualitative study to explore men and women's diabetes self-management experiences among the focus groups.

\subsection{Ethical Consideration}

The "ethics committee of the University of New South Wales, Australia" (Ref. No.: HC16882) and Pakistan's "Ayub Medical Institution" approved the study. Participants were recruited as a result of responding to recruitment advertisements and leaflets. The information sheet was provided to all participants detailing the purpose of the research, potential risks and benefits, and concerns about confidentiality, in addition to the informed consent form. The researchers were straightforward in communicating the study's purpose and methods to the participants. At any point, a volunteer could withdraw from the research. Each participant signed an informed consent form.

\subsection{Data Collection and Procedure}

Focus groups were utilized in this study because they encourage discussion about the challenges of diabetes self-management in the middle-aged population of rural Pakistan [21]. In general, group dynamics generate valid ideas because discussions between 
group members fosters diverse opinions and feelings [20]. The groups of males and females were separated for discussions as there are cultural limitations in the rural areas of Pakistan; in a male dominated society, women are unable to express their feelings openly [22].

Two sessions lasting approximately $50 \mathrm{~min}$ each were carried out. The discussion guide has been provided in Appendix A to initiate the discussions among the focus groups. This interview guide was also utilized by the authors who previously conducted the self-structured interviews for type 2 diabetes patients [22].

The authors explained the aims and objectives of this study to participants and they were informed that the discussions would be audio recorded and observations made to assure accurate data collection. The main author took part in the group activity, moderated the conversation, and prompted participants to share their experiences. The attendees were encouraged to share their stories and voice their concerns and ideas. Through engagement with others, they gained assistance and encouragement to express their opinions freely. The group activity ended once the participants no longer had thoughts or ideas to share.

\subsection{Data Analysis}

The data collected in this study were analyzed by thematic analysis because this method was developed to meet the needs of investigating the experiences, meaning, and reality of the participants [26]. Our thematic analysis involved initial independent coding by three academics. Thirty codes were identified in the preliminary analysis of the transcripts. Codes were then clustered and used to form nine sub-themes that integrated several of the originally identified codes and encompassed more general topics that were the focus of the transcripts. The detailed analysis led to the three major themes that illustrated the most significant and broad similarities or differences of diabetes self-management experiences of focus groups and barriers to self-management. These themes were further elaborated in the following section of results.

The following procedures were used to analyze the data: (1) all collected data, audio recordings, logs of observation, reflective conversations, and focus groups, were transcribed verbatim; (2) the transcripts were read repeatedly; (3) for the purpose of analysis, the sentences were shortened in the text; and (4) the discussions continued until all the authors agreed.

\subsection{The Study's Reliability}

The four dependability criteria were provided and applied to ensure the study's rigour $[27,28]$. The four criteria are as follows:

(1) True value: In order to enhance the true value of the analysis, the writers of this article examined data jointly, followed by the distribution of the article to six participants to review the article.

(2) Scope of Application: Confidentiality was assured for ideas voiced during the group sessions discussions by the participants to explore their experiences in a safe and trustworthy environment, resulting in extensive descriptions.

(3) Consistency: The researcher (the first author) led each group session and engaged personally in data collecting to avoid discrepancies in data collection procedures and the biases were avoided.

(4) Confirmability: The researcher checked and rechecked the data throughout the study to ensure the confirmability of the outcome of the data analysis.

\section{Results}

\section{Participant Characteristics}

Table 1 summarizes the participants' characteristics of this study $(n=20)$. Ten men and 10 women participated, ranging in age from 40 to 60 years (mean 55 years). Three participants had completed grade 9 education, four had completed school education, 10 completed education at the college level, and three had achieved a university degree. The majority of participants had married status and were employed. Men received diabetes 
therapy for an average of 12 years, while women had treatment for an average of 10 years. The individuals' mean glycated hemoglobin (HbA1c) level between men and women was (8.2 and 8.5) percent respectively.

Table 1. Summary of participant demographics $(n=20)$.

\begin{tabular}{|c|c|c|c|}
\hline Demographic & $\operatorname{Men}(n=10)$ & Women $(n=10)$ & Total $(n=20)$ \\
\hline Age (average, in years) & 58 & 52 & 55 \\
\hline \multicolumn{4}{|l|}{ Marital Status } \\
\hline Single/never married & 4 & 2 & 6 \\
\hline Married & 5 & 8 & 13 \\
\hline Separated/divorced & 1 & 0 & 1 \\
\hline Widowed & 0 & 0 & 0 \\
\hline \multicolumn{4}{|l|}{ Education } \\
\hline Less than grade 9 & 2 & 1 & 3 \\
\hline Some/completed high school & 2 & 2 & 4 \\
\hline $\begin{array}{l}\text { Some/completed college or } \\
\text { university }\end{array}$ & 6 & 4 & 10 \\
\hline Graduate/professional degree & 2 & 1 & 3 \\
\hline \multicolumn{4}{|l|}{ Employment } \\
\hline Full/part-time, self-employed & 8 & 7 & 15 \\
\hline Unemployed & 1 & 3 & 4 \\
\hline Retired & 1 & 0 & 1 \\
\hline Diabetes Duration (Mean years) & 12 & 10 & - \\
\hline HbA1c level (Mean \%) & 8.2 & 8.5 & - \\
\hline
\end{tabular}

Table 2 summarizes the analysis of the data resulting in three major themes: (1) diabetes as a challenging disease; (2) understanding diabetes and its challenges; (3) following diabetes self-management practices. These themes and sub-themes were discussed in detail in the context of the responses by the participants based on the detailed interview guide given in Appendix A for the two focus groups.

Table 2. Themes and sub-themes of self-management experiences of the middle-aged population in with type 2 diabetes in rural Pakistan.

\begin{tabular}{|c|c|}
\hline Main Themes & Sub-Themes \\
\hline Diabetes as a challenging disease & $\begin{array}{ll} & \text { Feelings of fatigue and fear } \\
\text { - } & \text { Blurred vision problem } \\
\text { - } & \text { Feeling hungry and thirsty }\end{array}$ \\
\hline Understanding diabetes and its challenges & $\begin{array}{ll}\text { - } & \text { Healthy diet and sugar control } \\
\text { - } & \text { Lack of physical activity } \\
\text { - } & \text { Emotions influencing Diabetes } \\
& \text { Self-management }\end{array}$ \\
\hline Following diabetes self-management practices & $\begin{array}{ll}\text { - } & \text { Diet challenges during social gatherings } \\
\text { - } & \text { Following physical activity schedule } \\
\text { - } & \text { Psychological burden with diabetes }\end{array}$ \\
\hline
\end{tabular}

\section{Theme 1:}

Diabetes Considered as "A Challenging Disease"

Patients with diabetes experience a range of discomfort, from disease diagnosis to the realization that the diabetes is irreversible. Throughout group discussions, individuals of varying ages and work position discussed their differing perspectives on the disease. The theme "diabetes considered as a challenging disease" brought three sub-themes for discussions, namely, the feelings of fatigue and fear, blurred vision, and feeling hungry and thirsty. 
Some of the participants had co-morbidities and were concerned about future consequences. Due to the unseen nature of consequences, participants referred to diabetes as a challenging disease:

One patient noticed some apparent bodily changes and signs:

"I am rather active at my workplace." However, if my physical power deteriorates significantly and I experience excessive exhaustion, I feel that my blood glucose level is gone up..." (Participant 14)

"I have a new sensation, one of 'fatigue,' which may be related to my low blood glucose level... After being diagnosed with type 2 diabetes, I am compelled to monitor any physical changes that occur to me." (Participant 15)

"I am living in terror of what may be impacted next. At the moment, I'm experiencing some nerve difficulties, which is really concerning..." (Participant 6)

Another concern that the middle-aged population confronts with diabetes is blurred vision.

"I've noticed that I' $m$ unable to see clearly but I used to see well, it also signals that I am suffering with some problem and may be my sugar level is elevated..." (Participant 5)

"I have blurred vision and experience dizziness on occasion... When I am unable to see clearly, my heart rate increases. Occasionally, my sugar level drops so low that I am unable to see well." (Participant 2)

One patient mentioned that:

"I have no idea when diabetes happened, I was feeling well, eating well but suddenly started feeling thirsty and hungry..." (Patient 10)

"The most challenging part is to cope with the conditions due to changes in our daily routines particularly after the diagnosis of the disease-that is the time we need more support to understand the impact of the disease and our health condition." (Patient 1$)$

\section{Theme 2:}

Understanding Diabetes and Its Challenges

The theme "understanding diabetes and its challenges" in focus groups interactions and discussions included three emergent sub-themes: (1) healthy diet and sugar control; (2) lack of physical activity; (3) emotions influencing diabetes self-management. During the group discussions, the participants shared their diverse perspectives, personal experiences of understanding diabetes, and its issues.

\section{Sub-Themes}

1. Healthy Diet and Sugar Control

In Pakistani culture, the terms "eating" and "food" have historically meant more than simply satisfying one's "physical need". The participants in the focus groups utilized their own language and situations to convey and further improve their understanding of a variety of experiences.

"I worked extremely hard for my career and was looking forward to enjoying delicious meals. I imagined that I might now have delicious meals daily and a great life. However, since being diagnosed with diabetes, I am unable to enjoy them at all." (Participant 5)

In group discussions and interactions, patients learned about the healthy food they need to eat as patients of diabetes. Though they are naturally not prohibited from eating these foods, they have to control what they eat.

The group members expressed a variety of viewpoints based on their personal experiences.

"I understand that there is no problem in consuming delectable cuisine; it simply means that we must exercise control over how we eat nutritious food..." (Participant 8) 
"We can still enjoy delectable healthful foods, but adherence to a balanced diet is important in order to maintain blood sugar..." (Participant 7)

One of the female participants mentioned:

"It is always difficult to cook the diabetic friendly food in a joint family set up. The food choices are very much dictated by the males living in the joint family." (Participant 9)

\section{Lack of Physical Activity}

Physical activity is crucial for diabetes patients to maintain a healthy blood glucose level. Patients discussed which exercises are appropriate for them and the effect of exercise on blood glucose control.

"It is critical to engage in physical exercise on a regular basis, as this uses glucose and is critical for blood glucose control." (Participant 9)

Patients discussed during group talks which exercises are appropriate and easy to carry out on daily basis and its benefits to manage their diabetes.

"I make it a point to workout at least three days a week. Every time, I chose to stroll for 30-40 min..." (Participant 8)

"It is physically difficult for someone in their sixties to run or jump. The only form of exercise available to us is strolling. . . After meals, I'll take a half-hour stroll..." (Participant 15)

\section{Diabetes Self-Management and Emotions}

Controlling nutrition over an extended period of time causes patients with diabetes to experience varying degrees of psychological stress. They shared their experiences in group talks about psychological adjustment approaches for cultivating positive awareness in order to activate pleasant emotions and further control diabetes.

"I know that eating cookies and cakes will increase my sugar level. However, I always eat cakes knowing that it brings high spikes to my blood sugar, I am emotionally influenced to continue doing it..." (Participant 7)

\section{Theme 3:}

Following Diabetes Self-Management Practices

The theme "following diabetes self-management practices" in focus group interactions and discussions included three emergent sub-themes: (1) dietary problems associated with social gatherings; (2) physical activity schedule; (3) psychological burden with diabetes. Following diabetes self-management practices is crucial for controlling the blood sugar and maintaining the healthy lifestyle. Diabetes self-management practices in day to day life involves overcoming diet challenges during social events, following a physical activity schedule, and coping with the psychological burden of diabetes. Therefore, patients with diabetes face great challenges in following up self-management practices.

\section{Sub-Themes}

1. Dietary Problems Associated with Social Gatherings

When confronted with restricted eating during special occasions, such as weddings and other events, patients frequently felt guilty if they did not restrict themselves and lost control. As a result, people with diabetes are constantly faced with the decision of whether to exercise self-control in such situations.

"It is courteous to decline invitations in social gatherings with friends. If I abstain from something or eat less during social gatherings, my friends become unhappy... However, when I lose self-control, I experience guilt..." (Participant 12)

\section{Adherence to a Physical Activity Schedule}

The most challenging aspect for diabetic people is adhering to a physical activity regimen. While patients understand the importance of exercise, they frequently lack the ability to actually perform it. 
"I am aware that I must exercise... However, I am powerless to perform it. I am aware that no one wishes to suffer from chronic hyperglycemia, and that everyone wishes to maintain control of their physical health and illness status..." (Participant 10)

\section{The Psychological Burden of Diabetes}

Diabetes patients must modify their lifestyles, which includes adjusting their daily meals, making sure that they do physical activities regularly, consistently monitoring blood sugar levels, and adhere to their prescribed regimen. The long-term application of these self-care routines and acceptance of restrictive life limits impose a major psychological cost on the middle-aged diabetic population.

"When I wake up in the morning, I ponder what should I eat and how much I consume... I need to get some workout. I am unable to take my medication till I have consumed food. I'm concerned that if I don't eat anything, my blood glucose will drop to low level... reduced activity may also result in poor glycemic control..." (Participant 12)

"Whatever I do, I must keep my diabetes in mind. I must monitor and manage my diabetes on a daily basis... to come to terms with the fact that my diabetes disease is for the rest of my life. It's quite challenging and stressful..." (Participant 14)

\section{Discussion}

This study focused on the individual (with type 2 diabetes), not the disease. Instead of medical clinics or healthcare centers, researchers interviewed individuals at the lecturers' auditorium or other locations of their choice. This way, participants felt more at ease discussing diabetes and self-management. Participants expressed concern about medical experts criticizing their diabetes self-management style, as they focus on $\mathrm{HbA1c}$ values rather than patient type 2 diabetes issues.

Patients are responsible for taking care of their diabetes daily as patients of type 2 diabetes must make several decisions and perform difficult tasks to maintain sufficient glycemic control [29]. For middle-aged people, making this decision is more difficult as their fantasy of enjoying a variety of delicious foods during this stage of life after a lifetime of hard work can be shattered by diabetes [22].

Patients who were diagnosed within 5 to 6 years with stable, acceptable glycemic control may require less professional help if they receive it within a short duration after diagnosis. Previous research has identified that stable individuals have distinct support needs compared to episodic or progressing patients [29]. Unpredictable disease might reduce self-efficacy, making patients feel less capable of self-management and hence more in need of help $[29,30]$.

The participants identified two instances of active self-management along their illness course. Patients reported inadequate self-management assistance, which is consistent with prior research [31]. They struggled to describe what is lacking, implying they are unsure about how the support can be improved. Patients of type 2 diabetes require selfmanagement support [32].

Thus, a detailed grasp of patients experiences on self-management and how it is currently understood and supported may benefit in the development of solutions that are better customized to the needs, preferences, and expectations of individual patients. Appropriate self-management assistance is expected to improve health outcomes and efficiency of care [13].

\subsection{Public Health Perspective}

The focus of this study on non-medical issues is a major plus. This study looked at selfmanagement from a public health perspective. A person-centered approach is important because patients are expected to manage type 2 diabetes on their own. Thus, the findings of this study may be used to design techniques that better support the self-management of 
patients with type 2 diabetes. User-centered design develops methods from the standpoint of the user (patient) and these solutions may boost acceptability of interventions as they are reflecting the patients' requirements and expectations [19].

Our findings indicate two critical considerations for developing user-centered selfmanagement support tools for people with type 2 diabetes. To begin, it is critical to provide support at the appropriate times, i.e., when patients require assistance due to changes in their daily routines or health. Our investigation discovered two such instances: immediately following diagnosis and when difficulties start (glycemic control deteriorates). In addition, previous research has demonstrated that as patients' health declines, their demand for self-management support increases [33].

\subsection{Clinical Perspective}

The qualitative study of two focus groups was carried out to gain a better understanding of the self-management experiences of rural areas of Pakistan's middle-aged population. The participants reported that diabetes is a silent disease with complications and presents numerous challenges to diabetes self-management. The effective diabetes treatment model is to ascertain the cause of a disease, accurately diagnose the disease, effectively treat the disease, and assist patients in recovering from the disease and regaining health [34].

However, patients who receive an accurate diagnosis of diabetes learn that the disease is incurable and must encounter a sequence of stressful events induced by the disease; this leads patients to interpret physical changes as warning indicators concerning their blood glucose levels [35]. Patients self-assessed their blood glucose levels and identified links between physical symptoms and blood glucose levels in this study. Patients of diverse ages and professional levels discussed how they might make sense of their current physical changes based on a variety of physical experiences during group interactions. Physical perception should be used to detect early symptoms, and detecting these warning signs prior to illness would assist diabetic patients in preventing disease onset [36].

Additionally, health care practitioners should consider ways to improve patients' self-observation of symptoms prior to beginning in order to further reduce the frequency of acute onset. Each individual's physical reaction to blood glucose levels is unique. If health care providers can assist patients in developing a connection with their bodies and empathize with the process of patient-centered disease empowerment, this will be meaningful development [37].

In rural Pakistan, meals are critical for the development of interpersonal ties. The traditional and cultural occasions and their associated family gatherings to celebrate these occasions put individuals with diabetes' food control to the test. According to relevant studies, the desire of individuals with diabetes to "not eat" at social events tends to isolate them from others [38]. We have found differences between the perception of selfmanagement of type 2 diabetes between men and women in this study. The preparation of food is managed by women in Pakistani culture but the choice of food is dictated by males. Therefore, it is extremely difficult to prepare healthy food for the patients with diabetes.

As a result, when "unhealthy food" (not suitable for patients with diabetes) is served at gatherings, diet management becomes challenging. During the discussions, it was determined that diet control, namely limiting the desire to eat, was the most difficult component for the participants and these findings are in agreement with the findings by Huang et al. [39].

The cultural predisposition needs to be acknowledged and accepted as a necessary component of the diabetes care approach. Healthcare professionals should relax institutionalized health education constraints and integrate diet control into daily life of the patients. Physical Activity is the most cost-effective therapy for diabetes control. It has been shown to decrease insulin resistance and delay the onset of problems [40]. The majority of participants in this study were of the opinion that physical activity is a critical component of diabetes therapy; nonetheless, they reported difficulty maintaining an exercise routine. 
However, the challenge for nurses is to incorporate physical activity into patients' everyday lives in order to further enhance the association between physical activity and disease, which is especially crucial for the middle-aged population. Lachance et al. [41] provided a compelling case that peer coaching and social support are beneficial for women's exercise self-management in communities. The current study proposes that diabetes care teams gradually increase the frequency of exercise management behaviors in the middleaged diabetic population during a typical workday and social occasions.

Diabetes is a chronic condition that requires lifelong management. Diabetes patients must maintain strict control over their lives, which demands psychological and behavioral modifications as well as self-management [1]. Accepting life limits and following long-term self-care norms is very difficult for many patients, adding to the middle-aged population's psychological burden. These groups require more assistance with diabetes self-management, including physical, psychological, and interpersonal assistance. According to Cryer [38], elderly diabetes patients have higher illness-related discomfort and are more likely to experience it than other age groups of diabetes patients.

Individuals who are ill frequently endure mood fluctuations as the illness worsens. As a result, health care practitioners should place a greater emphasis on educating middle-aged patients about illness management rather than focusing exclusively on physiological treatment. The way a patient adjusts to an illness is greatly dependent on the physician-patient relationship, and a physician's attention to a patient's psychological difficulties can significantly improve the patient's diabetic care outcome [32]. It has been established that offering high-quality diabetes self-management education to patients improves their selfmanagement [21].

Awareness of the complications from diabetes would help patients with diabetes to act with greater determination and motivation to carry out the self-management activities. The issue of awareness of complications is central because it is closely linked to the good medical practice of diabetes centers, particularly in rural areas [42]. The study carried out in Pakistan showed that people with diabetes have very low level of awareness about diabetes and its complications and management [43,44].

It is recommended that health care practitioners listen to their patients' self-management concerns and collaborate with them to develop strategies for making healthy lifestyle choices. Additionally, health-care teams should include clinical psychologists to assist patients in developing a more optimistic outlook on life, which will enable them to adjust to and coexist with the disease successfully.

\section{Strength and Limitations}

The main strength of this study is that it has provided culturally sensitive perspectives on the middle-aged population of rural areas of Pakistan with diabetes. The focus groups consisting of 10 women (group 1) and 10 men (group2) were divided and interviewed separately, provided excellent opportunity for women to express their point of view freely and without any reservations. This would have not been possible otherwise as women in rural areas of Pakistan are reluctant to express their point of view freely in front of male's participants. One of the limitations is related to selection bias: participants recruited had poor glycemic control; thus, they might have been more willing to take part in a clinical study in order to lower their HbA1c.

This study included outpatients at two clinics of the main hospital in Abbottabad's rural area; consequently, the study results may not accurately reflect the self-management requirements of all diabetes patients. Future studies should involve patients from a range of settings to ensure that our findings are generalizable. Second, the authors collected data on the diabetic self-management experiences of chosen focus groups at a single point in time; hence, the results may not accurately reflect an individual's perspective over time. 


\section{Relevance to Clinical Practice}

This study's findings highlight a number of critical areas, and addressing these critical areas may result in an improvement in the experience and self-management outcomes of patients with type 2 diabetes. In the first instance, emotional assistance is clearly needed, as many participants described diabetes as a significant and ongoing emotional and psychological burden. Several participants reported a need for diabetes education and information as information searching may be challenging for persons who are underprivileged or have limited health literacy. Furthermore, family involvement in such groups is also vital for their own education about diabetes and for receiving information on how to best support a family member with type 2 diabetes [45].

\section{Conclusions}

This study highlighted the experiences of Pakistan's middle-aged population in rural areas regarding diabetes self-management. Healthcare professionals should be involved in diabetes self-management education as soon as feasible to alleviate patients' concern and aggravation about their glucose level and symptoms. Along with self-management, health practitioners should focus on the diabetes self-management activities of the patients. Our findings can assist healthcare professionals in developing better patient-centered, culturally sensitive therapeutic abilities. In addition, it is required to form diabetes support groups in rural areas of Pakistan to help patients of diabetes to share their self-management experiences. The majority of patients with diabetes in rural Pakistan are unaware of diabetes complications. Therefore, community based awareness programs should be launched in primary health care clinics and hospitals to decrease the morbidity and mortality associated with diabetes mellitus.

Author Contributions: R.M.A. conducted the focus groups interviews, recorded, and transcribed the data. R.M.A. and H.H. analyzed and interpreted the patient data regarding the self-management of type 2 diabetes and drafted the manuscript. M.F.H. reviewed the work and provided extensive comments to improve the article. H.H. and N.Z. reviewed the manuscript and provided comments to enhance the overall presentation of the results. All authors have read and agreed to the published version of the manuscript.

Funding: This research received no external funding.

Acknowledgments: The authors like to express their gratitude to the participants in the focus groups for sharing their experiences.

Conflicts of Interest: The authors declare no conflict of interest.

\section{Appendix A}

Focus Group Interview/Discussion Guide

1. State your name, how long you've had diabetes for and why you decided to participate in the focus group.

- What was going on in your life when you found out you had diabetes? (Describe your overall experience living with and managing diabetes over the past year)

- Diet and nutrition

- Physical activity

- $\quad$ Taking medication

- Managing stress

- $\quad$ Care received

2. Overall, how well do you feel and think you are able to manage your diabetes?

3. What were your difficulties with having diabetes over the past year?

- Diet: social gatherings, watching what you eat

- Personal life

- Treatment 
- Fears/anxieties about having diabetes over the past year

4. What kinds of resources have been most helpful to you in managing your diabetes?

- How do your family/friends help you?

- Family physician

- Books/Magazine/Media

5. Describe your experience during your visits to the Diabetes Clinic/Center.

- Experience with the professionals and clerical staff

- Experience with the programs (one-on-one visits included)

6. How were your difficulties addressed during your visits to the Center?

- How were your fears/anxieties addressed during visits to the Center?

- Draw on prior answers for difficulties and fears

7. How would you like to see improvement in Diabetes Center services?

- $\quad$ Staff

- Resources

- Why didn't you come back to the Center?

- What would keep you going back to the Center?

8. Overall, describe your experiences accessing healthcare in regards to your diabetes

- Physician

- Hospital

- Specialists

9. Summarize the general themes of the focus group/ interview and ask:

- Is this a good representation of what was said?

- Does anyone else have anything to add?

- Does it spark any ideas for anyone of you?

\section{References}

1. Narayan, K.V. The Diabetes Pandemic: Looking for the silver lining. Clin. Diabetes 2005, 23, 51-52. [CrossRef]

2. International Diabetes Federation. IDF Diabetes Atlas, 9th ed.; International Diabetes Federation: Brussels, Belgium, 2019. Available online: http:/ /www.diabetesatlas.org (accessed on 24 August 2021).

3. Whiting, D.R.; Guariguata, L.; Weil, C.; Shaw, J. IDF Diabetes Atlas: Global estimates of the prevalence of diabetes for 2011 and 2030. Diabetes Res. Clin. Pract. 2011, 94, 311-321. [CrossRef]

4. World Health Organization. STEPS Surveillance Manual: WHO STEP Wise Approach to Chronic Disease Risk-Factor Surveillance; World Health Organization: Geneva, Switzerland, 2003.

5. Jafar, T.H.; Chaturvedi, N.; Pappas, G. Prevalence of overweight and obesity and their association with hypertension and diabetes mellitus in an Indo-Asian population. Can. Med Assoc. J. 2006, 175, 1071-1077. [CrossRef]

6. Ansari, R.M. Effect of physical activity and obesity on type 2 diabetes in middle-aged population. J. Environ. Public Health 2009, 2009, 195285. [CrossRef] [PubMed]

7. Koch, T.; Jenkin, P.; Kralik, D. Chronic illness self-management: Locating the 'self'. J. Adv. Nurs. 2004, 48, 484-492. [CrossRef]

8. Corbin, J.; Strauss, A. Unending Work and Care: Managing Chronic Illness at Home; Jossey-Bass: San Francisco, CA, USA, 1988.

9. Bodenheimer, T.; Wagner, E.; Grumbach, K. Improving primary care for patients with chronic illness: The chronic care model. JAMA 2002, 288, 1775-1779. [CrossRef]

10. Von Korff, M.; Gruman, J.; Schaefer, J.; Curry, S.; Wagner, E.H. Collaborative management of chronic illness. Ann Intern Med. 1997, 127, 1097-1102. [CrossRef] [PubMed]

11. Coleman, K.; Austin, B.T.; Brach, C.; Wagner, E.H. Evidence On The Chronic Care Model In The New Millennium. Health Aff. 2009, 28, 75-85. [CrossRef] [PubMed]

12. Furler, J.; Walker, C.; Blackberry, I.; Dunning, T.; Sulaiman, N.; Dunbar, J.; Best, J.; Young, D. The emotional context of selfmanagement in chronic illness: A qualitative study of the role of health professional support in the self-management of type 2 diabetes. BMC Health Serv. Res. 2008, 8, 214. [CrossRef] [PubMed]

13. Barlow, J.; Wright, C.; Sheasby, J.; Turner, A.; Hainsworth, J. Self-management approaches for people with chronic conditions: A review. Patient Educ. Couns. 2002, 48, 177-187. [CrossRef]

14. Chin, M.H.; Auerbach, S.B.; Cook, S.; Harrison, J.F.; Koppert, J.; Jin, L.; Thiel, F.; Karrison, T.G.; Harrand, A.G.; Schaefer, C.T.; et al. Quality of diabetes care in community health centers. Am. J. Public Health 2000, 90, 431-434. [CrossRef] [PubMed]

15. Mensing, C.; Boucher, J.; Cypress, M.; Weinger, K.; Mulcahy, K.; Barta, P.; Hosey, G.; Kopher, W.; Lasichak, A.; Lamb, B.; et al. National standards for diabetes self-management education. Diabetes Care 2007, 30 (Suppl. 1), S96-S103. [CrossRef] 
16. Norris, S.L.; Lau, J.; Smith, S.J.; Schmid, C.H.; Engelgau, M.M. Self-Management Education for Adults with Type 2 Diabetes: A meta-analysis of the effect on glycemic control. Diabetes Care 2002, 25, 1159-1171. [CrossRef]

17. Glasgow, R.E.; Strycker, L.A.; Toobert, D.J.; Eakin, E. The Chronic Illness Resources Surveys: A social-ecologic approach to assessing support for disease self-management. J. Behav. Med. 2000, 23, 559-583. [CrossRef]

18. Chrvala, C.A.; Sherr, D.; Lipman, R.D. Diabetes self-management education for adults with type 2 diabetes mellitus: A systematic review of the effect on glycemic control. Patient Educ. Couns. 2016, 99, 926-943. [CrossRef] [PubMed]

19. Powers, M.A.; Bardsley, J.; Cypress, M.; Duker, P.; Funnell, M.M.; Fischl, A.H.; Maryniuk, M.D.; Siminerio, L.; Vivian, E. Diabetes Self-management Education and Support in Type 2 Diabetes: A Joint Position Statement of the American Diabetes Association, the American Association of Diabetes Educators, and the Academy of Nutrition and Dietetics. Clin. Diabetes 2016, 34, 70-80. [CrossRef] [PubMed]

20. Webb, C. Focus groups as a research method: A critique of some aspects of their use in nursing research. J. Adv. Nurs. 2001, 33, 798-805. [CrossRef]

21. Polit, D.F.; Beck, C.T. Designing quantitative studies. In Nursing Research: Generating and Assessing Evidence for Nursing Practice, 10th ed.; Lippincott Williams \& Wilkins: Philadelphia, PA, USA, 2015; 784p.

22. Ansari, R.M.; Hosseinzadeh, H.; Harris, M.; Zwar, N. Self-management experiences among middle-aged population of rural area of Pakistan with type 2 diabetes: A qualitative analysis. Clin. Epidemiol. Glob. Health 2019, 7, 177-183. [CrossRef]

23. Carolan, M.; Holman, J.; Ferrari, M. Experiences of diabetes self-management: A focus group study among Australians with type 2 diabetes. J. Clin. Nurs. 2014, 24, 1011-1023. [CrossRef]

24. Wu, F.-L.; Tai, H.-C.; Sun, J.-C. Self-management Experience of Middle-aged and Older Adults with Type 2 Diabetes: A Qualitative Study. Asian Nurs. Res. 2019, 13, 209-215. [CrossRef]

25. Mathew, R.; Gucciardi, E.; De Melo, M.; Barata, P.C. Self-management experiences among men and women with type 2 diabetes mellitus: A qualitative analysis. BMC Fam. Pract. 2012, 13, 122. [CrossRef]

26. Braun, V.; Clarke, V. Using thematic analysis in psychology. Qual. Res. Psychol. 2006, 3, 77-101. [CrossRef]

27. Graneheim, U.H.; Lundman, B. Qualitative content analysis in nursing research: Concepts, procedures and measures to achieve trustworthiness. Nurse Educ. Today 2004, 24, 105-112. [CrossRef]

28. Lincoln, Y.S.; Guba, E.G. Implementing the naturalistic inquiry. In Naturalistic Inquiry; Sage Publications: London, UK, 1985; 416p.

29. Sandelowski, M. Rigor or rigor mortis: The problem of rigor in qualitative research revisited. ANS Adv. Nurs. Sci. 1993, 16, 1-8. [CrossRef]

30. Lorig, K.R.; Holman, H.R. Self-management education: History, definition, outcomes, and mechanisms. Ann. Behav. Med. 2003, 26, 1-7. [CrossRef]

31. Frei, A.; Svarin, A.; Steurer-Stey, C.; Puhan, M.A. Self-efficacy instruments for patients with chronic diseases suffer from methodological limitations-A systematic review. Health Qual Life Outcomes 2009, 7, 86. [CrossRef] [PubMed]

32. Nolte, E.; Knai, C.; Saltman, R. Assessing Chronic Disease management in European Health Systems: Concepts and Approaches; European Observatory on Health Systems and Policies, a Partnership Hosted by WHO: Copenhagen, Denmark, 2014.

33. Kujala, S. User involvement: A review of the benefits and challenges. Behav. Inf. Technol. 2003, 22, 1-16. [CrossRef]

34. Lai, W.A. Patient's "meanings of illness"-centered health care. Taiwan J. Fam. Med. 2017, 27, 32-41. [CrossRef]

35. Ling, Y.S.; Wu, Y.C. Exploring the characteristics of emotional state and the risk appraisal between the different depressive disposition and age groups for the diabetic. Arch. Clin. Psychol. 2005, 2, 64-75.

36. Chua, S.-S.; Ong, W.M.; $\mathrm{Ng}$, C.J. Barriers and facilitators to self-monitoring of blood glucose in people with type 2 diabetes using insulin: A qualitative study. Patient Prefer. Adherence 2014, 8, 237-246. [CrossRef]

37. Wu, F.-L.; Juang, J.-H.; Yeh, M.C. The dilemma of diabetic patients living with hypoglycaemia. J. Clin. Nurs. 2011, 20, $2277-2285$. [CrossRef]

38. Hsu, M.T.; Hsu, H.C.; Hsu, H.Y.; Wang, R.H. Disorder in life and the world: The illness experiences of women with diabetes in Taiwan. J Nurs. 2015, 62, 34-44. (In Chinese) [CrossRef]

39. Huang, C.-L.; Liu, M.-J.; Tai, Y.-K.; Chiou, C.-J.; Hsiao, J.-Y. Implementation and evaluation of a proper dietary behavior program in diabetes support groups. Hu Li Za Zhi J. Nurs. 2010, 57, 35-44. (In Chinese)

40. Ng, T.K.-W.; Kwan, R.; Lo, S.K.; Cheing, G. A Tailor-Made Exercise Program for Improving Balance and Mobility in Older Adults with Type 2 Diabetes. J. Gerontol. Nurs. 2018, 44, 41-48. [CrossRef] [PubMed]

41. Lachance, L.; Kelly, R.P.; Wilkin, M.; Burke, J.; Waddell, S. Community-Based Efforts to Prevent and Manage Diabetes in Women Living in Vulnerable Communities. J. Community Health 2017, 43, 508-517. [CrossRef] [PubMed]

42. UUllah, F.; Afridi, A.K.; Rahim, F.; Ashfaq, M.; Khan, S.; Shabbier, G.; Rahman, S.U. Knowledge of diabetic complications in patients with diabetes mellitus. J. Ayub Med. Coll. Abbottabad 2015, 27, 360-363.

43. Younis, H.; Younis, S.; Ahmad, S. Awareness regarding complications among diabetics in Pakistan. Inst. J. Endorsing Health Sci. Res. 2019, 7, 47-54.

44. Cryer, P.E. Hypoglycemia, functional brain failure, and brain death. J. Clin. Investig. 2007, 117, 868-870. [CrossRef]

45. Whitford, D.L.; Paul, G.; Smith, S.M. Patient generated "frequently asked questions": Identifying informational needs in a RCT of peer support in type 2 diabetes. Prim. Care Diabetes 2013, 7, 103-109. [CrossRef] 